\title{
Assessment of tuberculosis knowledge among Lesotho village health workers and utilisation of their tuberculosis services by the communities they serve
}

\begin{tabular}{|c|c|}
\hline $\begin{array}{l}\text { Authors: } \\
\text { Maseabata M } \\
\text { Ramathebane } \\
\text { Tiisetso J. Mak } \\
\text { Regina M. The } \\
\text { Motselisi Mok }\end{array}$ & $\begin{array}{l}\text { atjane } \\
\text { tsane } \\
\text { hethi (1) } \\
\text { het (D) }\end{array}$ \\
\hline $\begin{array}{l}\text { Affiliations: } \\
\text { Faculty of He } \\
\text { National Unive } \\
\text { Lesotho, Rom }\end{array}$ & $\begin{array}{l}\text { alth Science, } \\
\text { asity of } \\
\text {, Lesotho }\end{array}$ \\
\hline $\begin{array}{l}{ }^{2} \text { Faculty of Soc } \\
\text { National Unive } \\
\text { Lesotho, Rom }\end{array}$ & $\begin{array}{l}\text { ial Sciences, } \\
\text { rsity of } \\
\text { Lesotho }\end{array}$ \\
\hline $\begin{array}{l}\text { Correspondin } \\
\text { Maseabata Ra } \\
\text { mvramatheba }\end{array}$ & $\begin{array}{l}\text { author: } \\
\text { mathebane, } \\
\text { ne@gmail.com }\end{array}$ \\
\hline $\begin{array}{l}\text { Dates: } \\
\text { Received: } 14 \text { S } \\
\text { Accepted: } 27 \text { I } \\
\text { Published: } 31\end{array}$ & $\begin{array}{l}\text { ept. } 2018 \\
\text { Mar. } 2019 \\
\text { uly } 2019\end{array}$ \\
\hline $\begin{array}{l}\text { How to cite th } \\
\text { Ramathebane } \\
\text { Makatjane TJ, } \\
\text { Mokhethi M. } \\
\text { of tuberculosi } \\
\text { among Lesoth } \\
\text { workers and u } \\
\text { their tubercul } \\
\text { the communit } \\
\text { Afr J Prm Heal } \\
\text { Med. 2019;11 } \\
\text { https://doi.or\& } \\
\text { phcfm.v11i1.1 }\end{array}$ & $\begin{array}{l}\text { is article: } \\
\text { MM, } \\
\text { Thetsane RM, } \\
\text { Issessment } \\
\text { knowledge } \\
\text { o village health } \\
\text { tilisation of } \\
\text { sis services by } \\
\text { ies they serve. } \\
\text { th Care Fam } \\
(1), \text { a1944. } \\
/ 10.4102 / \\
944\end{array}$ \\
\hline $\begin{array}{l}\text { Copyright: } \\
\text { (c) 2019. The } A \\
\text { Licensee: AOS } \\
\text { is licensed unc } \\
\text { Creative Comr } \\
\text { Attribution Lic }\end{array}$ & $\begin{array}{l}\text { uthors. } \\
\text { S. This work } \\
\text { ler the } \\
\text { nons } \\
\text { ense. }\end{array}$ \\
\hline Read online: & \\
\hline 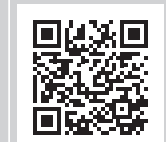 & $\begin{array}{l}\text { Scan this QR } \\
\text { code with your } \\
\text { smart phone or } \\
\text { mobile device } \\
\text { to read online. }\end{array}$ \\
\hline
\end{tabular}

Background: The role of village health workers (VHWs), among other roles is to educate communities about tuberculosis (TB), TB screening and its treatment. The knowledge of TB among VHWs is crucial because they will carry out their role at the community well and this will impact the overall outcome of TB treatment.

Aim: The study is aimed at assessing the knowledge of TB among VHWs and households at the village level and the utilisation of VHWs' TB services.

Setting: The study took place in 19 health centres from 10 districts of Lesotho.

Methods: The study used a cross-sectional descriptive design. Three study populations were interviewed, two at the household level (2040 households, 8295 individuals) and one at the clinic level (723 VHW).

Results: Overall, TB knowledge among VHWs for the majority of clinics except two was inadequate (below mean of 31.5). The utilisation of VHWs' TB services among community members was also low.

Conclusion: Low utilisation of VHWs' TB services by community members emanated from inadequate TB knowledge of VHWs. Regular refresher training among VHWs is recommended as the way forward in order to keep VHWs abreast with new TB developments.

Keywords: tuberculosis; inadequate knowledge; screening; treatment; village health workers; household.

\section{Introduction}

Worldwide community health workers (CHWs) are expected to promote good health practices in the community through health education in matters that are of concern in the country. 1,2,3,4 The most important matters of concern currently in Lesotho are a failure to meet Millennium Development Goals targets in HIV/AIDS, tuberculosis (TB), maternal and child mortality of which a village health worker (VHW) can play a vital role as one of the community members where she lives. ${ }^{2,5,6}$ For the VHWs to provide meaningful education to the community, he/she must have adequate information and knowledge about how to help to improve the health outcomes of $\mathrm{TB}^{2,3,7}$ hence the need to establish the level of knowledge of VHWs against the Ministry of Health's VHWs training manual curriculum. It is equally important to establish if VHWs had access to refresher courses to periodically refresh their knowledge.

The criterion used for the selection of VHWs is stipulated in the Ministry of Health and Social Welfare (MOHSW) training manual and is in line with practices in other countries. ${ }^{7,8}$ According to the criterion for a person to be selected, he or she must be a full-time resident of the village with no other responsibilities. He or she must be elected by the village itself and be literate. He or she must be in good health and be an adult between the ages of 25-70 years. VHWs must have the following attributes: be a dedicated, trainable, and respected member of the community. He or she must be a person who maintains confidentiality and can work on a voluntary basis. ${ }^{6,7}$ In Lesotho, VHWs are seen as members of a primary health care team supervised by a nurse from the nearby clinic or health centre. ${ }^{8,9} \mathrm{He}$ or she serves as a link between the community and primary health care facility. ${ }^{7}$

According to MOHSW (2011:9), VHWs operate through home visits, small group discussions and community gatherings. ${ }^{7}$ They must assist the village in developing and maintaining a safe water supply and sanitation; ${ }^{9}$ identify village health needs and facilitate the use of village health 
resources to meet these needs; ${ }^{10}$ assist the health centre team in controlling disease outbreaks and assist the chief with vital statistics (births and deaths registration); promote good nutrition and recognise, manage and organise follow-ups for under-nourished children; ${ }^{9}$ identify and provide initial treatment of diseases such as diarrhoea and vomiting; 9 recognise, refer and organise follow-ups of TB patients; ${ }^{11}$ provide first aid and home-based care; participate in health centre meetings; keep patient records and report monthly activities to the health centre nurse; cooperate with development extension workers. ${ }^{6,9}$

An in-depth analysis of CHWs by Perry and Zullinger (p. 1) $)^{5}$ found that CHWs work under varied conditions and have a wide range of work environments and expectations. ${ }^{5}$ There are also disparities in the time taken to train VHWs where some have only a few days of training, while others have 6 months or more of training. In Lesotho, training of VHW is stipulated in the VHWs training manual by the Ministry of Health (MOH). For someone to qualify as a VHW, he or she must have completed 6 weeks of training using the $\mathrm{MOH}$ training manual. ${ }^{6,7}$ Competency of VHW has to be measured and improved through refresher courses for them to provide the expected services. ${ }^{6,10}$ Education for CHWs should include training on the more logistical aspects of their jobs, such as household entry, community sensitisation, data collection and recording, and relevant ethical issues mainly on how to maintain confidentiality. ${ }^{6}$

In 2003, Lesotho came up with an essential service package that specifies the role of VHWs, while in 2011 revitalisation of the health services strategy was established. These two strategies clearly specify the role of VHWs. Accordingly the health centre nurse has to provide supportive supervision to the VHWs and ensure that records are kept and available for inspection. 7,9 There should be an organogram for the VHW which includes $\mathrm{CHW}$ supervisor and $\mathrm{CHW}$ coordinator, and the nurse who is part of the supervisory structure; this is highlighted by Rachlis et al. ${ }^{6}$ (p. 3) showing that there is a community health extension worker whose role is to supervise a group of CHWs. ${ }^{6}$ This allows the nurse to focus more on the clinical role and receive reports from the $\mathrm{CHW}$ coordinator who is based at the clinic, whose duties include collating information received from the $\mathrm{CHW}$ supervisors and submitting this to the nurse and clinic administrator.

Performance management should be carried out based on a standardised set of skills that respond with community needs. ${ }^{10}$ The programmes should have regular and continuous supervision and monitoring systems in place and supervision should be taught and undertaken in a participatory manner that ensures two-way flow of information. ${ }^{10}$ Other than assessing access to health care through VHWs, ${ }^{9}$ the researchers are not aware of any assessment study of TB knowledge of Lesotho's VHWs. As the effectiveness of village health work is premised on the knowledge of VHWs, it is important that their knowledge is regularly evaluated. Other than providing feedback that could inform the training curriculum and the frequency of refresher courses, for Lesotho this is even more important as TB is among the top ten causes of death in the country. The long history of Basotho men working the South African mines and the association between TB and mine work could explain the high prevalence of TB in the country. An assessment of TB knowledge among VHWs, which has never been done before in Lesotho, is required if the country aims to improve $\mathrm{TB}$ treatment outcomes through community health care services. The study therefore has two objectives, namely to assess TB knowledge among the VHWs and to assess utilisation of VHWs' TB services by the communities they serve.

\section{Methods}

The study was conducted in Lesotho between 2016 and 2017 and covered all 10 districts in Lesotho. The study used a cross-sectional descriptive design. Three study populations were interviewed, two at the household level and one at the clinic level. The first sample was all household members whose information was provided by the head. The second sample was all present household members aged 15 years and above and a total of 1958 household members were interviewed. The third study population was made up of all VHWs serving in the selected clinics and 723 VHWs were interviewed.

The formula:

$\mathrm{n}=\left\{p(1-p)(1.96)^{2} / d^{2}\right\}$,

[Eqn 1]

where $p$ is the anticipated proportion $(0.50)$ and $d$ is the precision (0.05) required on either side of the proportion, estimated around the $95 \%$ confidence interval, was used to estimate the number of households within the catchment of the selected villages to be sampled. As the information on the number of community members receiving help from VHWs for HIV and/or TB treatment was not available, it was assumed, that $50 \%$ of the households within the community received help from the VHW, for purposes of sample size estimation. Furthermore, as the study utilises the multistage cluster sampling method, the sample size is multiplied by the design effect $(D=2)$, plus a non-response rate of $10 \%$. The estimated sample was 1200 households to the nearest 100. Lesotho's population distribution by ecological zone was used to distribute households to be visited per clinic.

To maximise representativeness of the clinics in the sample, the health service area (HSA) concept was utilised where the country was divided into 17 catchment areas found around 17 hospitals in the country. Each hospital was responsible for supervising clinics within its catchment area. The distribution of health services was in accordance with the terrain of the country which has lowlands, foothills, mountains and the Senqu River. The 17 HSAs were used as clusters from which clinics were selected to represent each cluster. As there are clinics supervised or visited by Lesotho Flying Doctors Service (LFDS) and those supervised by the District Health Management Team (DHMT), clinics under LDFS and DHMT formed the 18th and 19th clusters. 
Random numbers were used to select a clinic to represent each cluster. All data collection tools were uploaded on the Open Data Kit (ODK). All research assistants, supervisors and data managers signed a confidentiality form. Research assistants collected data using smart phones or tablets. Once the questionnaire was completed and checked for completeness, the information was submitted electronically to the server. If the research assistant was working in an area where there was no mobile network, completed files were queued and sent to the server immediately after the research assistant reached an area with a mobile network. Only blank forms were kept on the cell phone or tablet of the research assistant. In the event of the smart phone getting lost or stolen, the forms were still secure because one needs a password to access them. Only the data manager and the supervisors knew the passwords other than the research assistants. Data were collected between September and November 2016.

Eight questions were constructed to test for TB knowledge among VHWs. For each question, correct options were listed and the research assistant would tick the correct ones mentioned. The list of options was taken as is from the training manual. At the analysis stage, a code of 1 was given for the correctly mentioned options and a code of 0 was given for those not mentioned. To measure knowledge, a summary measure was computed by adding the responses of each question. In a question with four options, a summary score of 0 denoted that no correct option was mentioned, while a score of 4 would mean all correct options were mentioned. The options for each question ranged between 3 and 10 . Overall knowledge was the summary of all the questions. To measure adequate knowledge, Nachega, Lehman, Hlatshwayo et al.'s (2005) definition of adequate knowledge was used. ${ }^{12}$ According to this definition, an individual must know at least $75 \%$ of the items used in the summary variable to qualify for adequate knowledge.

All data collection tools were translated from English into Sesotho. The Sesotho version of the tools was used for training both supervisors and research assistants. Tools were pretested to check if they were collecting required information. To avoid community complains with respect to why some households were visited while others were not visited, research assistants were to visit each household within the selected village even if that meant going beyond the number of households for the clinic. On the other hand, if the households of the selected villages fell short of the target, even if by five households, another village had to be included in the sample and all households in the village were to be visited not just the additional five to meet the target. This approach has resulted in almost double (2140 instead of 1200) the number of households visited.

At the household level, the head was asked to report on all household members if they had ever been diagnosed with TB. For those who had ever been diagnosed, the head was to report if the VHW helped the member with TB treatment. For household members aged 15 years and above, five questions were asked, namely about how TB is spread from one person to another the causes of $\mathrm{TB}$, whether $\mathrm{TB}$ can be cured, the signs that someone could be suffering from TB and whether the respondent was advised by the VHW to do a screening for TB. These five questions were addressed to respondents who acknowledged knowledge of TB. For the household level questions, the options for questions included known myths about TB.

As the assessment of knowledge was based on the information contained in the training manual, questions were formulated using what VHWs had been taught during training. The exceptions were questions on the profile of VHWs such as age and the year of training. As VHWs would teach what they had been taught during training, questions for members of the community were also based on the training curriculum of VHWs. As this was the first assessment for the country, we had nothing with which to benchmark the tools.

Data were analysed in November 2016 using Statistical Package for Social Scientists (SPSS) version 20. Goodwill permission to conduct the study was obtained from the 19 selected clinics. All the study participants gave their written informed consent. Key information pertaining to treatment of TB comparing the performance of clinics was prepared and taken to the clinics to validate with all VHWs participating in the study.

\section{Ethical considerations}

Ethical approval was obtained from the National Ethics and Review Board of the Ministry of Health - registration number 188-2016 (Reference number: ID73-2016).

\section{Results}

\section{Characteristics of household members}

In total 2040 households were visited during the survey with a population of 8295 individuals. Regarding the profile of household members, more than a third (37\%) of the household members are children while grandchildren constitute $17 \%$. More than half (52\%) were females and $48 \%$ were males. Forty-two per cent of the household members were aged less than 20 years, while $13 \%$ were aged 60 years and above. About a fifth $(17 \%)$ of the members were absent from the household, while $82 \%$ were present. More than half $(54 \%)$ of the household members had finished their primary level education compared to a quarter $(25 \%)$ who had done secondary education or better. Less than $40 \%$ (38\%) of the household members were never married compared to $47 \%$ and $16 \%$ of them either currently married or previously married, respectively. Table 1 presents the profile of household members.

\section{Characteristics of village health workers}

More than 700 (723) VHWs responded to the VHW questionnaire. The age distribution of VHWs is bell shaped. It increases from a low of $18 \%$ for those aged less than 40 years 
TABLE 1: Characteristics of the household population.

\begin{tabular}{|c|c|c|c|}
\hline Characteristic & Category & $\%$ & $N$ \\
\hline \multirow[t]{8}{*}{ Relationship to head } & Head & 23.8 & 1970 \\
\hline & Spouse & 12.4 & 1031 \\
\hline & Child & 37.0 & 3068 \\
\hline & Son- or daughter-in-law & 1.9 & 156 \\
\hline & Grandchild or great grandchild & 16.8 & 1391 \\
\hline & Other relative & 6.4 & 535 \\
\hline & Other person not related & 1.6 & 132 \\
\hline & No response & 0.1 & 12 \\
\hline \multirow[t]{3}{*}{ Sex } & Male & 47.8 & 3963 \\
\hline & Female & 52.2 & 4326 \\
\hline & No response & 0.0 & 6 \\
\hline \multirow[t]{6}{*}{ Age } & $00-10$ & 18.8 & 1559 \\
\hline & 10-19 & 22.9 & 1902 \\
\hline & $20-29$ & 16.1 & 1338 \\
\hline & $30-59$ & 24.7 & 2046 \\
\hline & $60+$ & 13.2 & 1095 \\
\hline & Age not stated & 4.3 & 355 \\
\hline \multirow[t]{6}{*}{ Residential status } & Present & 81.8 & 6786 \\
\hline & Visitor & 0.6 & 49 \\
\hline & Member elsewhere in Lesotho & 9.2 & 761 \\
\hline & Member outside Lesotho & 8.2 & 681 \\
\hline & Do not know & 0.1 & 6 \\
\hline & No response & 0.1 & 12 \\
\hline \multirow[t]{3}{*}{ Marital status } & Never married & 37.8 & 2162 \\
\hline & Currently married & 46.7 & 2669 \\
\hline & Previously married & 15.5 & 884 \\
\hline \multirow[t]{6}{*}{ Level of education } & Pre-school & 3.3 & 273 \\
\hline & Primary & 54.1 & 4489 \\
\hline & Secondary and above & 25.0 & 2077 \\
\hline & Other & 0.2 & 14 \\
\hline & Do not know & 0.5 & 44 \\
\hline & Aged less than 5 or no response & 16.9 & 1398 \\
\hline
\end{tabular}

and reaches a peak of $28 \%$ for those aged between 50 and 59 years. Almost all VHWs are females (93\%), while the majority (64\%) are currently married and a third (33\%) were previously married. More than two-thirds (77\%) of the VHWs had completed primary education and a fifth had completed secondary education or higher. Almost all VHWs (94.6\%) reported that they were trained by the $\mathrm{MOH}$ and were mostly trained after 1999 while refresher courses were concentrated between 2010 and 2016. Table 2 shows the profile of VHW.

\section{Tuberculosis knowledge among household members}

The majority (87.9\%) of the household members aged 15 years and above who had ever heard of TB knew that TB is spread through the air when coughing or sneezing. Wrong modes of spreading TB such as touching someone who has TB, sharing food or utensils with someone who has TB or unprotected sex as well as mosquito bites were also mentioned by the remaining $12 \%$ of the respondents. As shown in Figure 1, 78.5\% mentioned one wrong mode of spreading $\mathrm{TB}$, while 18 respondents mentioned two wrong modes of spreading TB. Less than $5 \%$ mentioned or identified at least three wrong modes of spreading TB. Touching someone who has TB or sharing utensils with someone who has TB was mentioned by $6 \%$ of the respondents, while sharing food with someone who has $\mathrm{TB}$, sexual contact or mosquito bites was mentioned by
TABLE 2: Profile of village health workers.

\begin{tabular}{|c|c|c|c|}
\hline Characteristic & Category & $\%$ & $N$ \\
\hline \multirow[t]{3}{*}{ Sex } & Male & 6.6 & 48 \\
\hline & Female & 93.2 & 674 \\
\hline & No response & 0.1 & 1 \\
\hline \multirow[t]{6}{*}{ Age } & $<40$ & 18.0 & 130 \\
\hline & $40-49$ & 25.4 & 184 \\
\hline & $50-59$ & 28.1 & 203 \\
\hline & $60-69$ & 22.8 & 165 \\
\hline & $70+$ & 5.2 & 38 \\
\hline & No response & 0.4 & 3 \\
\hline \multirow[t]{4}{*}{ Marital status } & Never married & 2.2 & 16 \\
\hline & Currently married & 64.4 & 467 \\
\hline & Previously married & 33.2 & 241 \\
\hline & No response & 0.1 & 1 \\
\hline \multirow[t]{4}{*}{ Education } & No education & 1.2 & 9 \\
\hline & Primary & 77.4 & 561 \\
\hline & Secondary or higher & 21.2 & 154 \\
\hline & No response & 0.1 & 1 \\
\hline \multirow[t]{3}{*}{ Who trained you? } & Ministry of health & 94.6 & 684 \\
\hline & Partner In Health, world vision, global health & 2.9 & 21 \\
\hline & No training & 2.5 & 18 \\
\hline \multirow[t]{6}{*}{ Year of training } & Before 1990 & 9.3 & 67 \\
\hline & 1990-1999 & 14.7 & 106 \\
\hline & 2000-2009 & 28.6 & 207 \\
\hline & 2010-2016 & 38.6 & 279 \\
\hline & Do not remember & 6.4 & 46 \\
\hline & No training & 2.5 & 18 \\
\hline \multirow{6}{*}{$\begin{array}{l}\text { Year of refresher } \\
\text { course }\end{array}$} & Before 2000 & 1.8 & 12 \\
\hline & 2000-2009 & 5.8 & 42 \\
\hline & 2010-2016 & 58.8 & 420 \\
\hline & Do not remember & 20.5 & 147 \\
\hline & No refresher course & 11.6 & 84 \\
\hline & No training & 2.5 & 18 \\
\hline
\end{tabular}

$\mathrm{PIH}$, partners in health.

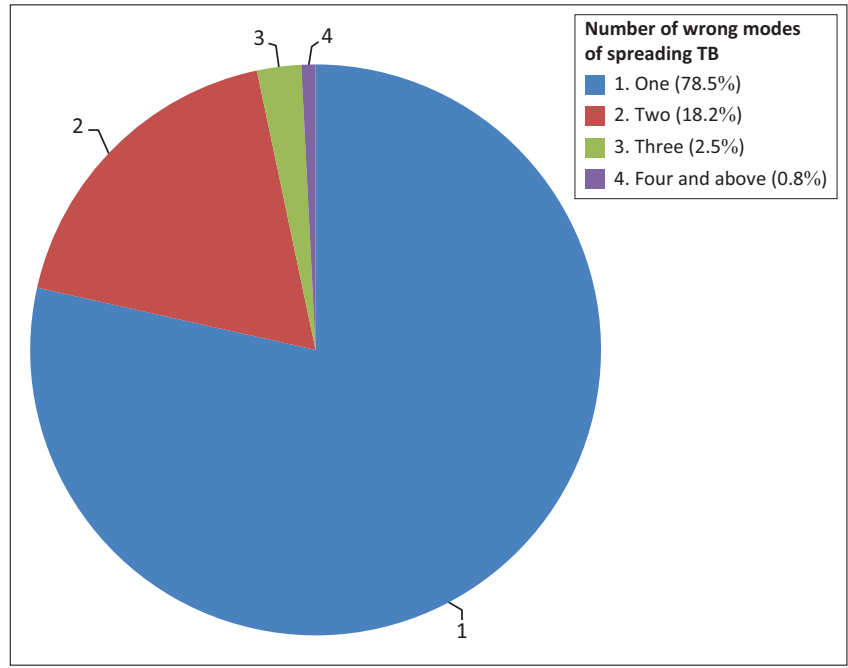

FIGURE 1: Number of wrong modes of spreading tuberculosis mentioned (\%).

less than $3 \%$. Figure 1 shows the number and percentage of wrong modes of spreading TB mentioned.

Concerning the knowledge of symptoms for someone for who has TB, $28.1 \%$ of the respondents knew at least 4 of the 9 symptoms. One in five knew between 1 to 3 symptoms, while $11.3 \%$ knew none of the symptoms. Coughing continuously 
for 2 weeks was the most known symptom mentioned by $52 \%$ of the respondents followed by sweating at night mentioned by $48.7 \%$. Coughing with sputum, loss of appetite and weight loss were mentioned by between $30.4 \%$ and $38.9 \%$. Fever, chest pains and tiredness or fatigue were mentioned by between $10.5 \%$ and $14 \%$, while blood in sputum was mentioned by $20.8 \%$ (Figure 2). Figure 2 shows the number and percentage of known symptoms that someone has TB.

With respect to what causes $\mathrm{TB}, 41 \%$ of the respondents knew that TB is caused by microbes or germs or bacteria found in the air. More than half of the respondents were of the view that TB is caused by other causes including inheritance from parents, smoking, alcohol drinking, exposure to cold temperatures and dust. Smoking (32.5\%), dust (29.7\%) and alcohol consumption (15.8\%) to a larger extent were the major culprits believed to cause TB. The other non-causes of TB were mentioned by between $2.9 \%$ and $8.7 \%$. However, only less than $5 \%$ of the respondents who associated causes of TB with wrong modes associated TB with at least 4 wrong causes, while the majority (51\%) associated it with one wrong cause (Figure 3). Figure 3 depicts the number and percentage of non-TB causes mentioned.

\section{Tuberculosis knowledge among village health workers}

Generally speaking there was inadequate TB knowledge among VHWs. There were, however, disparities across the indicators. For knowledge about signs that someone has TB and what can be observed after completion of TB treatment, the shortfall between the observed and expected mean was $25 \%$ and $33 \%$ for the knowledge of side effects of TB drugs. The highest disparity was for the knowledge of side effects of multi drug resistance (MDR) TB with a short fall of $67 \%$. For the remaining measures the shortfall was between $50 \%$ and $57 \%$. Table 3 shows the mean knowledge of TB among VHWs. For the overall knowledge, the shortfall between the observed and the expected is more than $50 \%$ (53.9\%). It is noteworthy

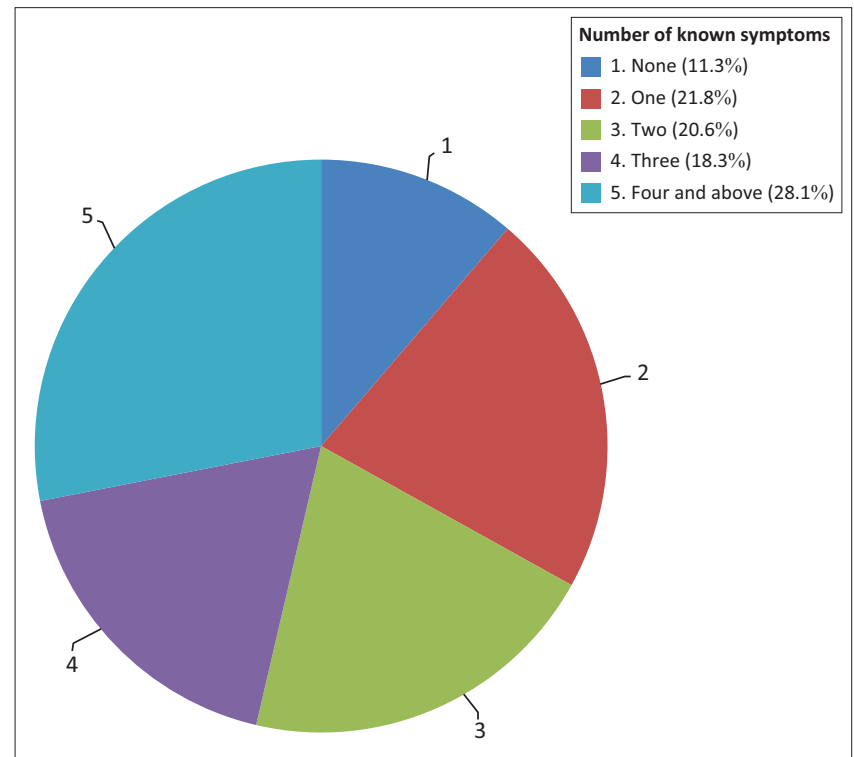

FIGURE 2: Number of known symptoms that someone has tuberculosis (\%). that at the clinic level, VHWs of two clinics had adequate knowledge with a mean of 32.96 and 37.00. Table 3 presents the knowledge of TB among VHWs.

\section{Utilisation of village health workers' tuberculosis services}

Responding to who helped the household members to be on TB treatment, the household head reported that a third (34.9\%) of those diagnosed with TB were helped by the VHW. Among the household members aged 15 years and above, more than a third $(36.9 \%)$ reported that they were advised by the VHW to go for TB screening (see Figure 4).

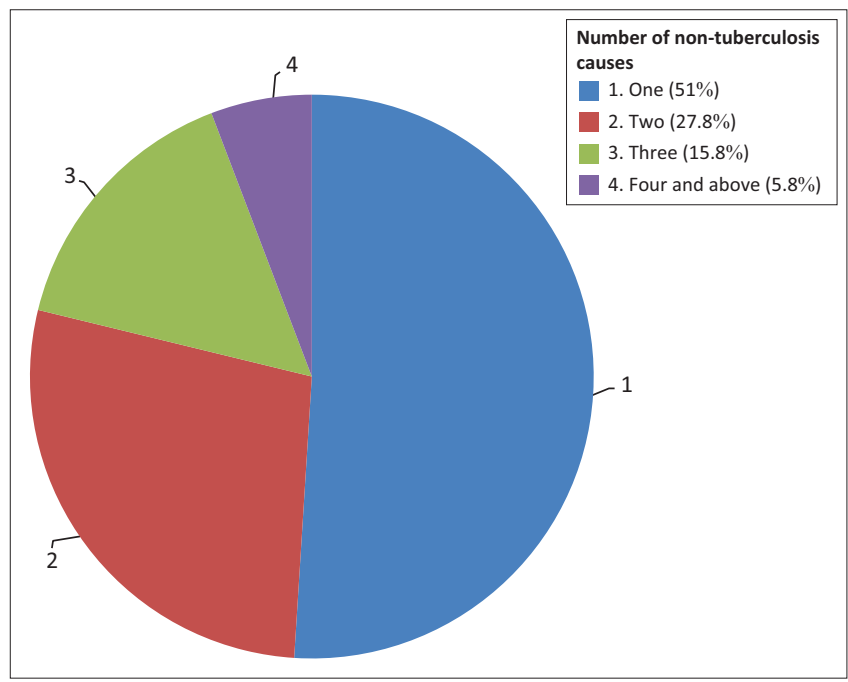

FIGURE 3: Number of non-tuberculosis causes mentioned (\%).

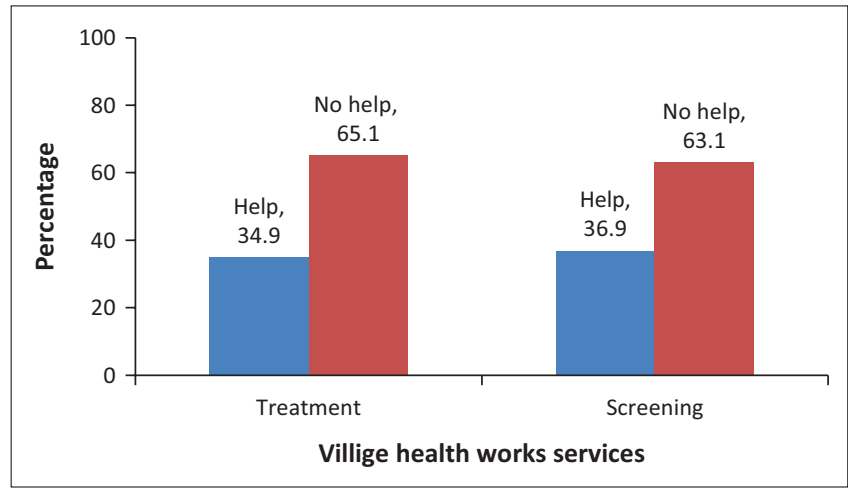

FIGURE 4: Percentage of household members who received help from village health workers for tuberculosis treatment or screening.

TABLE 3: Knowledge of tuberculosis among village health workers.

\begin{tabular}{lccc}
\hline Knowledge summary measure of: & $\begin{array}{c}\text { Observed } \\
\text { mean }\end{array}$ & $\begin{array}{c}\text { Expected } \\
\text { mean }\end{array}$ & $\boldsymbol{N}$ \\
\hline Signs that someone has TB & 3.28 & 4.50 & 6 \\
Predisposing factors for TB infection & 2.30 & 4.50 & 6 \\
Ways of preventing the spread of TB infection & 2.22 & 3.00 & 4 \\
Some side effects of TB drugs & 2.78 & 7.50 & 10 \\
Some side effects of MDR-TB treatment & 2.27 & 6.75 & 9 \\
Importance of TB treatment & 1.71 & 2.23 & 3 \\
What may be observed after completion of TB treatment & 2.41 & 3.00 & 4 \\
Overall knowledge & 14.55 & 31.50 & 42 \\
\hline
\end{tabular}

Note: $N$ denotes number of responses used to compute the summary measure. Expected mean is based on Nachega et al.'s definition of adequate knowledge..$^{12}$ $\mathrm{TB}$, tuberculosis. 
One reported about advice to go for TB screening (selfreported), while the other reported about help to get TB treatment (household head). However, both reports were similar in terms of the utilisation of services of the VHW which is estimated at around $33 \%$. Figure 4 presents the utilisation of the VHWs' TB services by community members and the percentage of household members who received help from VHWs for TB treatment or screening.

\section{Discussion}

Generally speaking, there is inadequate TB knowledge among Lesotho's VHWs. The disparity between observed mean knowledge and expected knowledge is huge. The low utilisation of the VHWs' TB services among community members was not surprising because of inadequate TB knowledge among VHWs. Understandably, community members served by a VHW with inadequate knowledge are less likely to utilise VHWs' TB services. This finding confirmed what was suggested by the literature, namely that adequate knowledge among VHWs would translate into high or better utilisation of VHWs' services. ${ }^{13,14,15}$

The information on the profile of VHWs (Table 2) does not offer any explanation about the prevailing inadequate knowledge among VHWs. According to Table 2, close to 6 in $10(58.8 \%)$ VHWs had had refresher training recently, between 2010 and 2016, ruling out the lack of a refresher course as the main factor behind inadequate knowledge. It is important to further investigate factors behind inadequate knowledge among VHWs, more so because all VHWs (94.6\%) except one or two claimed to have been trained by the $\mathrm{MOH}$. The practices of the two clinics with adequate knowledge might share some light about why VHWs from other clinics are not performing accordingly.

\section{Limitations of the study}

What emerged during the course of conducting the study was that clinics operate differently and, during the planning stages of the study, no adequate steps were taken to control for some of the differences. One major difference was the presence or absence of a VHW coordinator although this was in less than five clinics. Unlike in circumstances where there is no coordinator, the coordinator has enough time to attend to VHWs' problems and concerns, thus creating an enabling environment. One other difference was that in some clinics, partners in health provided additional remuneration to VHWs which boosted their morale. Such dynamics ought to have been taken into consideration if the study was not the first of its kind. Future studies should take the differences in the way clinics function into consideration when assessing factors associated with inadequate TB knowledge.

\section{Conclusion and recommendations}

Inadequate TB knowledge among Lesotho's VHWs and the communities they serve is the cause for concern. Improved TB treatment outcomes are not likely to be realised in the near future before inadequate TB knowledge among VHWs is addressed through rigorous training. It might also be in order to investigate the perceptions of community members on the role of the VHWs in their villages. This is particularly so because it is common knowledge that patients or their relatives, in particular people living with HIV, get nothing when VHWs are compensated for reporting on their status. As Basotho respect their local authorities and take their word to be final, local authorities need some orientation on the work of the VHW so that both the village chief and the VHW can come to an understanding.

\section{Acknowledgements}

The authors acknowledge the assistance of the Ministry of Health through its facilities, primary health care clinics, hospitals and District Health Management Team. The staff provided all the required assistance. They also acknowledge the chiefs for allowing them to enter their villages for data collection and the VHWs for guiding them and responding to the VHW questionnaires. They thank a strong group of team leaders, supervisors and research assistants. They acknowledge the National University of Lesotho for affording them the time for this important research. They thank Mr L. Mphatsi, Mr K. Keta and Ms Lephoto for making the work easier through the Open Data Kit and translation of questionnaires. Finally, they thank Dr Pearl Ntsekhe and Mrs Phangisile Mtshali of the Bristol Meyer Squibb Foundation (BMSF).

\section{Competing interests}

The authors declare that they have no financial or personal relationships that may have inappropriately influenced them in writing this article.

\section{Authors' contributions}

M.V.R. covered the literature review and analysis, presentation of the results and preparation of the manuscript. T.J.M. covered the research design, including the sampling techniques recommendations and the proofreading of the article. R.M.T. covered the data collection, data analysis and discussions. M.M. covered the literature review, data collection, editing of the manuscript and recommendations.

\section{Funding information}

The study was funded by the Bristol Myers Squibb Foundation.

\section{Data availability statement}

Raw data are available for reanalysis if required.

\section{Disclaimer}

The views expressed in this manuscript are those of the authors and not necessarily of the institutions the authors are affiliated with nor the institution on whose behalf the assessment was done, as well as the sponsor. 


\section{References}

1. Bedelu $\mathrm{M}$, Ford $\mathrm{N}$, Hilderbrand $\mathrm{K}$, et al. Implementing antiretroviral therapy in rural communities: The Lusikisiki Model of decentralized HIV/AIDS care. J Inf Dis. 2007;196(Suppl 3):S464-S468. https://doi.org/10.1086/521114

2. Ministry of Health and Social Welfare (MOHSW). Designing an essential service package for the Lesotho Health Sector. Final report. Ministry of Health and Socia Welfare; 2003.

3. Keith JJ, Rigodon J, Cancedda C, et al. Lay health workers and HIV care in rura Lesotho: A field report. AIDS Patient Care STDs. 2012;26(3):141-147. https://doi. org/10.1089/apc.20110209

4. Mwai GW, Mburu G, Torpey K et al. Role and outcomes of community health workers in HIV care in sub-Saharan Africa: A systematic review. J Int AIDS Soc. 2013;16(1):18586. https://doi.org/10.7448/IAS.16.1.18586

5. Perry $\mathrm{H}$, Zullinger R. How effective are community health workers? An overview of current evidence with recommendations for strengthening community health worker programs to accelerate progress in achieving the health-related Millennium Development Goals. Baltimore, MD: Johns Hopkins Bloomberg School of Public Health; 2012.

6. Rachlis B, Naanyu V, Wachira J, et al. Community perceptions of community health workers (CHWs) and their roles in management for HIV, tuberculosis and hypertension in Western Kenya. PLoS One.2016;11(2):e0149412. https://doi. org/10.1371/journal.pone.0149412

7. Ministry of Health. Village health worker trainers manual. Maseru; Ministry of Health; 2011.
8. Crigler L, Hill K, Furth $\mathrm{R}$, et al. Community health worker assessment and improvement matrix (CHW AIM): A toolkit for improving community health worker programs and services. Published by the USAID health care improvement project. Bethesda, MD: University Research Co., LLC (URC); 2011.

9. Kumar M, Nefdt R, Ribaira E, et al. Access to healthcare through community health workers in East and Southern Africa. UNICEF report. New York: UNICEF; 2014.

10. World Health Organization (WHO), The Global Health Worker Alliance. Global experience of community health workers for delivery of health related Millennium Development Goals: A systematic review, country case studies, and recommendation for integration into National Health Systems. WHO; 2010. Geneva.

11. Khabo M, Matinhure S, Maema M. Lesotho village health worker profiling and mapping exercise report. Maseru: USAID; 2013.

12. Nachega JB, Lehman DA, Hlatshwayo D, et al. HIV/AIDS and antiretroviral treatment knowledge, attitudes, beliefs and practices in HIV infected adults in Soweto, South Africa. J Acquir Immune Defic Syndr. 2005;38(2):196-201. https:// doi.org/10.1097/00126334-200502010-00011

13. Hirsch-Moverman $Y$, Daftary A, Yuengling KA, et al. Using mHealth for HIV/TB treatment support in Lesotho: Enhancing patient-provider communication in the START study. J Acquir Immune Defic Syndr.2017;74(Suppl 1):S37-S43. https://doi. org/10.1097/QAI.0000000000001202

14. Howard AA, Hirsch-Moverman $Y$, Frederix $K$, et al. The START Study to evaluate the effectiveness of a combination intervention package to enhance antiretroviral therapy uptake and retention during TB treatment among TB/HIV patients in Lesotho: Rationale and design of a mixed-methods, cluster-randomized trial. Glob Health Action. 2016;9(1):31543. https://doi.org/10.3402/gha.v9.31543

15. Braun R, Catalani C, Wimbush J, et al. Community health workers and mobile technology: A systematic review of the literature. PLoS One. 2013;8(6):e65772. https://doi.org/10.1371/journal.pone.0065772 